\title{
Libraries and Mexican American Bibliography
}

Mexican American bibliographies which are prepared as guides to the holdings of one library many times fall short of their potential: These works often do not mention some of the basic sources; they lack search strategies for the unsophisticated user; their arrangement does not promote accessibility; they attempt to reflect the holdings on several minority groups; and they do not mention standards for inclusion. To remedy these defects, the following article suggests seven criteria to improve Chicano bibliographies and provides five titles of exemplary works in this field.

\begin{abstract}
$\mathrm{T}_{\mathrm{r}}$ T. ity of the Mexican AMERicans forced many colleges to improvise courses in Chicano Studies in the 1960s. To complement this tempo of sudden recognition of America's second largest minority group, librarians often responded by putting together Chicano bibliographies to serve as guides to their holdings.

Unfortunately, almost all of these locally prepared bibliographies reflect the haste and the urgency of their inception and completion. Their compilers, perhaps indifferently reacting to an assignment and feeling secure under the anonymity of corporate authorship, aggravated an already desperate situation by presenting to the public hastily conceived bibliographies that neither represented their Mexican American holdings nor directed the user. Perhaps the blame for this shoddiness can be placed on exigencies of the moment or librarians
\end{abstract}

Richard D. Woods is chairman, Latin American Studies, Trinity University, San Antonio, Texas. reacting to a fad course whose duration would entail little bibliographical control. Yet it is possible that librarians do not deserve all the blame. Their efforts may reflect the inadequacy of Mexican American materials in many collections in the $1960 \mathrm{~s}$.

However, now we are well out of the 1960 s and have the perspective to know that Chicano studies or at least interest in the Mexican American is not ephemeral. Publications on this topic have accelerated; the movement has proven its durability; and the focus presently is on bilingual education with its auxiliary emphasis on biculturalism. Now is the moment to inventory and to assess what librarians have done in Chicano bibliography and to establish guidelines to improve the bibliographical control of this growing field of knowledge.

In completing a manuscript on Chicano reference material, ${ }^{1}$ I recently examined over 270 bibliographies, many of which were generated by libraries attempting to provide some guide to information on this ethnic group. In my study of these guides I found a pattern of errors that continued to recur and an 
abundance of worthless or marginal works that would frustrate the user. The guidelines or criteria that I suggest for a successful or at least an adequate bibliography of an institution's holdings result from this study of Chicano reference materials. The following is not only a list of tentative standards but also a critique of current Chicano bibliographies produced by librarians.

\section{Seven Criteria}

1. Mexican Americans deserve singular attention. This means that materials relating to this group should not share space with similar materials on Eskimos, Orientals, Blacks, and American Indians. In the Southwest, because of Chicano concentration and for historical reasons, a collective ethnic bibliography is inexcusable. If this pluralism is ever justifiable, it would have to include the Chicano with more kindred groups such as the Cuban and the Puerto Rican.

2. The bibliographer should establish the guidelines for the work in a preface or an introduction. Two pages are sufficient to indicate a compiler's intention and the limits established for the work: justifications, time periods, formats, and arrangement. In these prefatory remarks it should be noted what the compiler has done with the subject of Mexico. If the bibliographer has attempted to include all or even a portion of the library's works on this country, then there has been created a pseudo Chicano bibliography pre-empted by tithes that displace works tied more culturally and geographically to the Mexican American.

An easy solution is to list only the books from Mexico or Latin America that directly pertain to the Chicano. For example, Los Chicanos: una minoría nacional explotada, by Gilberto López y Rivas, though from Mexico, relates closely to the Mexican American. Another possibility is a Spanish name dictionary such as Onomástica hispano- americana, by Gutierre Tibón, who attempts to trace the origin of surnames and who provides a work of reference value for any Hispanic culture. But the whimsical inclusion of Mexican titles dilutes the bibliography and misleads the user. A suggested compromise might be to mention a reputable Mexican bibliography with the entries checked which are in the library.

3 . Before the bibliography proper, it is wise to offer explanatory paragraphs on how to use the collection best in order to secure more Mexican American materials. Students, uninitiated in the subtleties of library research, may be unaware of the terminology and the number of subject headings that could reveal additional sources. They may also forget to check such basic references as the New York Times Index, ERIC, various other services, and government documents.

4. Not only should the above be included to maximize the usefulness of the bibliography, but also some generally neglected resources that rightfully belong in Mexican American literature. Many compilers forget the body of American literature that preceded the formalized Chicano movement. Such novels as John Steinbeck's Tortilla Flat or Willa Cather's Death Comes for the Archbishop surely deserve attention in any Chicano bibliography.

A checklist of titles of this nature is available in the valuable study by Cecil Robinson, With the Ears of Strangers, The Mexican in American Literature. ${ }^{2}$ He surveys the entire field to determine the images of the Mexican evoked in Anglo literature. Noting mainly negative stereotypes, Robinson presents his most important assessment in the chapter, "Children of the Earth."

Excluding the views of the dominant culture, compilers sometimes also forget to incorporate non print materialsslides, tapes, and films. For a visually oriented generation, these sources might 


\section{4 / College \& Research Libraries • January 1977}

be of greater value than the more traditional ones.

5. In arranging the bibliography, the tendency to divide it by subject fields leads to duplicating entries, making judgmental decisions as to placement of titles, and unintentionally marking lacunae. Certain titles of value, such as anthologies, because of the hybrid nature of their contents are susceptible to entry under various fields. A remedy, perhaps as time consuming as the compilation of the bibliography but ultimately beneficial to the user, is thorough indexing. Alphabetical listing by author and title requires little effort, but a subject index presupposes an awareness of content and an ability at cross-referencing. The latter eliminates the need for a classified bibliography and yet allows for multiple listings of interdisciplinary works.

6 . The selections in the bibliography most difficult to locate and assess are general works. Even though not mentioning the Chicano as part of an ethnic group, these classic studies treat such factors as poverty, migrant workers, the nature of prejudice, assimilation in the United States, the education of the culturally different, and unemployment in the Southwest. They provide the context in which to place Chicanos and understand their problems.

Prior reading, that is, before referring to works specifically on the Mexican American, is recommended as an introduction to a study of this ethnic minority. Since the titles, tables of contents, introductory remarks, and even evaluative book reviews do not allow the librarian to detect their relevance to the Chicano, another tactic must be exploited to find these works. Probably the easiest method to identify such titles will be through faculty members who have expertise in the several fields.

The inclusion of seminal works is the mark of a highly useful bibliographical tool. Three examples serve to illustrate the type of material that belongs in this category: Uprooted Children: The Early Life of Migrant Farm Workers, by Robert Coles; The Nature of Prejudice, by Gordon Allport; and Poverty in America, by Louis A. Ferman.

7. My final suggestion perhaps is utopian. Yet with the intensified production of Chicano materials any bibliography upon publication becomes obsolete. Therefore, regular supplements, especially in research libraries or those in the Southwest, should be mandatory. Such a tool serves to update the bibliography and alerts the librarian when sufficient material is available to warrant a revised edition.

\section{EXEMPLARY WoRKS}

These are suggestions, not commandments, to aid librarians in redoing their bibliographies or in initiating guides on Chicanos for their own collections. Although most of the works of this nature need revisions, several are exemplary. All from the 1970s, the following excel because of perspective or maturity within the field of Chicano bibliography. No one incorporates all of these suggestions ( several may actually contradict them), but each is worth emulating because of some bibliographical feature that facilitates use or expands and refines control of Mexican American studies within one collection.

Ethnic Studies: A Selective Guide to Reference Materials at Berkeley was compiled by Phyllis Bischof and published in $1974 .^{3}$ It is a selective and annotated guide to bibliographies, abstracts, indexes, and other reference works. In addition to entries, Bischof describes the card catalogs and the various library units and offers suggestions on use of periodical literature, abstracts, and bibliographies. This appears to be a distillation of the experiences and 
thoughts of a reference librarian who understands user needs. Although I do not agree with the multiplicity of ethnic groups included, I find this bibliography commendable for its annotations of Chicano works and its foresight in bringing the user to generally overlooked materials.

Another outstanding reference work, Mexican Americans: A Selected Bibliography Revised and Enlarged, Fall 1974, is a guide to a cross section of the materials at the University of Houston libraries. ${ }^{4}$ It has approximately 1,450 unannotated entries on the title topic, Spain, and Mexico, and general items, such as Oscar Handlin's The Uprooted, The Epic Story of the Great Migrations that Made the American People. The section on literature, one of the best developed in bibliographies of this nature, includes Mexican novels, Chicano selfportrayals, and Anglo interpretations.

Especially noteworthy as an invaluable guide to materials on Mexican Americans is Finding Chicano Materials in the Michigan State University Libraries. ${ }^{5}$ Noting terminology, subject headings, the peculiar tools necessary for using each format, this bibliography has a purpose unique to the fieldto familiarize the inexpert user not only with Mexican American materials but also with the most appropriate search strategy for locating this information.

Steven Tash and Karin Nupoll, in $L a$ Raza: A Selective Bibliography of Library Resources, have compiled one of the largest guides to Mexican American materials: books, periodicals, articles, filmstrips, government documents, and microfilms. ${ }^{6}$ The 3,173 sporadically annotated entries fall into three large categories-Mexicans, Mexican Americans, and general sources. The latter, an aspect often ignored in bibliographies, refers to books on prejudice, delinquen- cy, the exceptional child, etc. The three categories are in turn subdivided under twenty-four separate subject headings. To aid the user further, Tash and $\mathrm{Nu}$ poll divide these into reference and general resources. On the whole, the work is excellent because of its completeness and facility of use.

Finally, one more work merits attention. Mary Butterfield's A Bibliography and Guide to Chicano Materials in the Eastern Michigan University Library has 116 annotated entries from various contributing disciplines of Chicanismo. ${ }^{7}$ Because of annotations, subject indexing, the interdisciplinary nature of the materials and the three-page guide on how to research the subject, Butterfield's guide is superior to most other library bibliographies.

\section{ConcLusion}

Because the major contributions derive only from five works, the essence of this review is both negative and corrective. The number of failures, or at best neutral examples in the field of Chicano bibliography, is indicative of the state of Chicano studies-a groping for identity, an unsureness of direction, and the creation of a few works based on scholarship and imagination.

Because of the many poorly done works, little impression is given of evolvement or development, i.e., newer bibliographies perfecting earlier efforts. Until recently this apparently has not been done. My suggestions for improvement plus the brief discussion of five superior bibliographies may serve as a formula for currently projected works on the Mexican Americans. Librarians with such guidelines can produce bibliographies that incorporate more materials, that possess an arrangement which promotes accessibility, and that include search strategies to encourage the fuller use of resources. 


\section{REFERENCES}

1. Richard D. Woods, Reference Materials on Mexican Americans: An Annotated Bibliography (Metuchen, N.J.: Scarecrow, 1976).

2. Cecil Robinson, With the Ears of Strangers: The Mexican in American Literature (Tucson: Univ. of Arizona Pr., 1963).

3. Phyllis Bischof, Ethnic Studies: A Selective Guide to Reference Materials at Berkeley ([Occasional Publications, 1] Berkeley: Univ. of California, The General Library, 1974).

4. University of Houston Libraries, Mexican Americans: A Selected Bibliography Revised and Enlarged, Fall 1974 (Houston, Texas: Univ. of Houston Libraries, 1974).
5. Michigan State University Libraries, Finding Chicano Materials in the Michigan State University Libraries ([How to Find Series, no. 1] East Lansing, Mich.: Michigan State Univ. Libraries, 1973).

6. Steven Tash and Karin Nupoll, comps., La Raza: A Selective Bibliography of Library Resources (Northridge, Calif.: California State Univ., Northridge, 1973).

7. Mary Butterfield, A Bibliography and Guide to Chicano Materials in the Eastern Michigan University Library (Ypsilanti, Mich.: Eastern Michigan Univ. Library, 1972). 